\title{
2006-912: LIBERAL ARTS AND TECHNOLOGICAL LITERACY
}

Douglass Klein, Union College

Douglass Klein is Professor of Economics and Director of the Center for Converging

Technologies at Union College.

\section{Robert Balmer, Union College}

Dr. Balmer is Emeritus Dean of Engineering and Computer Science and Professor of Mechanical Engineering at Union College in Schenectady New York. Before coming to Union he was Professor and Chair of the Mechanical Engineering Department and Associate Dean in the College of Engineering and Applied Science at the University of Wisconsin-Milwaukee. He has industrial experience at Westinghouse and DuPont, and is a registered professional engineer. Dr. Balmer has BS and MS degrees in Mechanical Engineering and a BS degree in Engineering Mathematics from the University of Michigan, and an ScD degree in Mechanical Engineering from the University of Virginia. He is the author of over 60 articles on a variety of theoretical and experimental engineering topics, and published an Engineering Thermodynamics textbook in 1990. His current research includes engineering education pedagogical research, the study of electrostatic energy generation in moving dielectric materials, and general applications of non-equilibrium thermodynamics. 


\title{
Engineering, the Liberal Arts, and Technological Literacy
}

\begin{abstract}
It is high time to address and bridge the historical gulf between engineering and the liberal arts in higher education. Both engineering and liberal arts educators should not merely view this as an interesting sideline, but rather as an educational imperative in order to introduce students to the new interdisciplinary ideas that are changing the landscape of global society and, to "minimize the threat of terminal incompetence." Can we continue to produce liberal arts graduates who have little understanding of the technological world in which they live? Can we afford to produce engineers with little understanding of the implications of those technologies for the world? This paper addresses the concept of technological literacy for $21^{\text {st }}$ century undergraduates and proposes an agenda for a new liberal arts curriculum which we call "Converging Technologies" which emphasizes both "technology" and "literacy."
\end{abstract}

\section{Introduction}

It is high time to address and bridge the historical gulf between engineering and the liberal arts in higher education. Both engineering and liberal arts educators should not merely view this as an interesting sideline, but rather as an educational imperative in order to introduce students to the new interdisciplinary ideas that are changing the landscape of global society, and to "minimize the threat of terminal incompetence." How long can we produce liberal arts graduates who have little understanding of the technological world in which they live? How long can we afford to produce engineers with little understanding of the implications of those technologies for the world?

This paper addresses the concept of technological literacy for $21^{\text {st }}$ century undergraduates, and proposes an agenda for a new liberal arts curriculum which emphasizes both "technology" and "literacy." The traditional liberal arts curriculum has its roots in 1000 years of educational history, and is by nature and design slow to change. Such change can only be brought about by a strong coalition of top leaders in academia and government, and it must be done soon.

Union College, a small private liberal arts college with engineering, is experimenting with a new undergraduate paradigm for integrating the arts, humanities, and sciences with modern technology and engineering. This paradigm, called "Converging Technologies" $(\mathrm{CT})^{2}$, examines the new and often unexpected technological opportunities and technological challenges that appear at the interfaces of traditional academic disciplines, and focuses creative thought on those emerging ideas that are changing the landscape of global society. Above all, the CT programs under development at Union College seek to extend the traditional liberal arts goal of educating informed and responsible citizens to encompass the increasingly dominant role of technology, and this goal applies equally to engineering and liberal arts graduates. CT programs further seek to foster dialog across the disciplines, both to recognize and capitalize on the innovative new ideas to be found in the intersections, and to address complex challenges that also lurk there. 


\section{Background: Engineering, Liberal Arts, and the Two Cultures}

George Bugliarello, President Emeritus and former Chancellor of the Polytechnic University has written that: "Today's conflicts between the views that the humanities hold of science and engineering and the views science and engineering hold of the humanities weaken the very core of our culture. Their cause is lack of integration in today's education among subjects that hark back to the medieval trivium and quadrivium." ${ }^{, 3,4} \mathrm{He}$ feels that integration of intellectual activity is urgently needed because no field can be learned in isolation today. In terms of societal leadership, $21^{\text {st }}$ century technology is so complex and so pervasive that no one can lead effectively without understanding the practical implications of technological decisions.

Bugliarello's views echo those of the now legendary 1959 Rede Lecture by physicist C. P. Snow on the two cultures. Nearly fifty years later, as specialization in all fields continues unabated, the problem is not solved. It was recently raised once again on the $100^{\text {th }}$ anniversary of Snow's death in an essay in the Chronicle of Higher Education. ${ }^{5}$ Snow may have been a bit uneven in his assessment of the two sides of the issue, siding with the scientists as the bearers of truth, but he was certainly correct in noting that there was a failure to communicate.

The new generation of liberal arts and engineering faculty are more aware of the blurring of disciplines, especially in the sciences and engineering, and of the increased interest in the impact of technology on society. As a consequence, faculty are more accepting of new directions and collaborations. The new awareness is coming from directions as diverse as an NSF study on Converging Technologies ${ }^{6}$, to the Dalai Lama ${ }^{7}$, and many points in between. ${ }^{8}$ Whatever undergraduate major a student chooses, and whatever job that student aspires to, the world demands that the student's education include the breadth to be able to communicate across Snow's academic cultures.

\section{A mandate for technological literacy in higher education}

The first thing most people think of on the subject of technology literacy is bringing students in non-technical fields up to some minimum level of technical understanding. In 1994, the International Technology Education Association (ITEA) launched its Technology for All Americans Project (TfAAP ${ }^{9}$ ) as an organization to seek ways to advance student attainment of technological literacy. They began by defining technological literacy broadly as follows.

Technological literacy is the ability to use, manage, assess, and understand technology. It involves knowledge, abilities, and the application of both knowledge and abilities to real-world situations. Citizens of all ages benefit from technological literacy, whether it is obtained through formal or informal educational environments.

While TfAAP focuses it activities on achieving technological literacy in K-12, its vision is clearly universal. It goes on to state:

Technological literacy is far more than the ability to use technological tools.

Technologically literate citizens employ systems-oriented thinking as they interact with the technological world, cognizant of how such interaction affects individuals, our society, and the environment. 
Their goal was to create a vision of what it means to be technologically literate, how this can be achieved, and why it is important to the future of the United States.

This goal was further explained with the 1996 publication of "Technology for All Americans: A Rationale and Structure for the Study of Technology (Rationale and Structure)" which concludes:

Technological literacy is much more than just knowledge about computers and their application. It involves a vision where each citizen has a degree of knowledge about the nature, behavior, power, and consequences of technology from a broad perspective. Inherently, it involves educational programs where learners become engaged in critical thinking as they design and develop products, systems, and environments to solve practical problems.

Close reading of TfAAP suggests that, while the authors may have had primarily in mind teaching technology to the technically illiterate, the goal cuts both ways. The goal includes the ability to "manage, assess, and understand technology." Thus it is not enough to know how it works or how to build it, the technologically literate citizen must be able to manage and assess technology. Thus, TfAAP places burdens on all sectors of education - both liberal arts and engineering - to create more well-rounded graduates.

The national efforts of TfAAP are directed at K-12, but shouldn't there also be a similar effort in higher education? Sadly, in the recent publication by the Association of American Colleges and Universities (AACU), "Liberal Education Outcomes: The Learning Every Students Needs" 10 there is no mention of technological literacy. Instead they focus on the necessity of skills that include inquiry, critical and creative thinking, information literacy, and quantitative literacy. These might be construed as technological literacy without using the unacceptable " $\mathrm{t}$ " word, but in practice it generally does not interpreted that way.

At Union College we believe that well educated citizens of the $21^{\text {st }}$ century should be technologically literate problem solvers We need leaders who understand that the solution to one problem may have impact many other problems, and who recognize the relationships between technology, people, society, and the environment.

We believe that technologically literate liberal arts college graduates are an amalgam of artist, humanist, scientist, and engineer. These graduates understand the importance of new technological developments. They understand how society can be reshaped by technological advances and can assess the impact and consequences of new technological systems, and they are prepared to talk to one another.

\section{Converging Technologies as an Educational Paradigm for the $21^{\text {st }}$ Century}

What does the phrase "Converging Technologies" mean? The phrase originated in the communications industry, referring to the convergence of voice, data, and video in the digital era. The phrase has evolved to refer to the new and often unexpected technologies that appear at the interfaces of existing fields of study. The National Science Foundation offers four examples of such technologies: Nano, Bio, Info, and Cogno technologies (NBIC). At first blush, because 
of the word "Technologies," this seems to refer only to science and engineering, but as used at Union, and increasingly by others, we mean the ways that technologies intersect not just with one another, but with all other areas of human endeavor. It really includes all fields in higher education from philosophy to art to music to modern languages and beyond, because all of the traditional disciplines can intersect in some way with technology ${ }^{11}$.

Why is it important? It is important to the future of our students and our society. Abbott and Masterman put it best: "Students who do not understand how the new and converging technologies work, how they construct meaning, how they can be used, and how the evidence they present can be weighed and evaluated are, in contemporary cultures, considerably disadvantaged and disempowered."12 The increasing pace of technological change places more urgency on the problem. The Dalai Lama comments that "Seeing the tremendous importance of science [he also addresses technology] and recognizing its inevitable dominance in the modern world fundamentally changed my attitude to it from curiosity to a kind of urgent engagement.",13 and Mihaly Csikszentmihalyi, author and presidential advisor observes, "In the past, we were like passengers on the slow coach of evolution. Now, evolution is more like a rocket hurtling through space, and we are no longer passengers, but its pilots. What kind of human beings are we going to create?"14

Engaging students with technology, with the implications and control of technology, and with one another, is our challenge. Union's Center for Converging Technologies, established in the Fall of 2002, works with faculty and students across the College, and extends into the regional community to build curriculum and scholarship that supports interdisciplinary approaches to the challenges and opportunities brought on by technology. Most specifically, the Center for CT seeks to build bridges between engineering and the liberal arts, but more generally, we seek to eliminate, or at least begin bridging C.P. Snow's gulf.

On the curriculum side, Union has introduced new interdisciplinary programs in Nanotechnology (funded by the National Science Foundation), Bioengineering and Computational Biology (funded by the Howard Hughes Medical Institute), Neuroscience, and Science, Medicine and Technology in Culture. We have also enhanced traditional liberal arts areas with courses such as arts and technology, cryptology, and the history and philosophy of science and technology.

Our newly-established Center for the Analysis of Productivity and Entrepreneurship (CAPE) is pursuing an entrepreneurship-across-the-curriculum strategy. This year, with encouragement and support from CAPE, there will be courses which include concepts of entrepreneurship, not just in Economics and Engineering (where we might expect to find them), but also in Classics, Visual Arts, History, Political Science, and Physics. CAPE's emphasis is that an entrepreneurial spirit serves well in pursuing any goal.

The College recently adopted a new Core Components Curriculum, to replace its existing General Education requirements. The Core Components will be required of both engineering and liberal arts students, and offer several excellent opportunities for interdisciplinary dialogue. One core requirement will be a sophomore research seminar, which will be taught on various topics, by faculty from across the campus. A second opportunity comes in the form of three- 
course clusters, currently being designed, which will require students to choose courses related by a common theme or problem, but offered by different departments or divisions within the College. The Center for CT is working with faculty to create as many of these seminars and clusters involving technology as possible.

One very important aspect of the engineering education at Union College is the expectation that all engineers have a significant international experience. Among all Union students, approximately sixty percent have an international experience, but among engineers, the figure is closer to ninety percent. There are a number of ways of satisfying this expectation, but among the most successful from a CT perspective is a set of three-week "miniterms" offered on technology-related themes that appeal to both engineering and non-engineering students. Topics include water resource management in Brazil, alternative electric power in New Zealand, and geographic information systems to map historic sites in Cordoba, Spain.

In the area of research, we have encouraged interdisciplinary teams that bridge the engineering-liberal arts divide. Our progress to date has been primarily in bridging science and engineering, on subjects like insect vision, heart stress monitors, and aerogel fabrication. We expect, through sophomore research seminars and senior research projects, to engage broadly interdisciplinary teams to address technology-related problems in the surrounding community.

As we build new programs, we are also engaged in a long range facilities planning process, working with ideas from Project Kaleidoscope (pKAL) ${ }^{15}$ to guide our thinking about shared, flexible spaces, well-placed common spaces.

\section{Conclusions: Getting from Here to There, and Quickly, Please}

Everyone seems to agree that increased technical literacy among the nation's citizens is important, and growing more so by the day. For one thing, this means that non-engineers should be able to make informed decisions through an understanding of technology. For another thing, it means that scientists and engineers should be able to responsibly predict and explain the likely effects of their work. And finally, technical literacy means that everyone must be able to communicate with one another about matters technical. The burden of achieving this literacy falls on both sides of the engineering-liberal arts divide. We advocate a new and broader definition of the liberal arts which includes technology along with the traditional liberal disciplines. We are not alone in noting "the importance of broadening and coordinated engineering and liberal arts curricula," 16 and our approach is very much to view this as a campus-wide effort, not one driven by either engineering or the liberal arts sides.

Change in academia has always been difficult. It has often been said that: "Changing a university is like moving a grave yard - you do it one faculty grave at a time!" So, how do we implement curricular change in academia?

The kind of institutional change we propose is not new to Union College, and that gives us an advantage. In1795 Union College became the first college chartered by the Regents of the State of New York. In the 1820s, when the classical curriculum was the most widely accepted field of study, Union introduced a bachelor's degree with greater emphasis on history, science, 
modern languages, and mathematics. Science and technology became important concerns; chemistry was taught before 1809, a degree in scientific studies was added, and in 1845, Union became the first liberal arts college to offer engineering. In 1895 the Electrical Engineering program was initiated and from 1902 to 1913 it was headed by the "electrical wizard" of the General Electric Company, Charles P. Steinmetz.

Today Union continues to offer an outstanding engineering education in a contemporary liberal arts context. We provide students with a solid foundation for a professional career as well as an understanding of the liberal arts, and a mastery of the principles that allow students to serve as leaders to advance technology in a socially responsible manner.

Still, even for a school with a history of innovation, challenges exist. We are not alone. The Committee on Facilitating Interdisciplinary Research of the National Academies of Science and Engineering list a number of key areas in which colleges and universities must adapt to foster greater interdisciplinarity. ${ }^{17}$ Based on this report, we have developed our own list of issues to address in implementing the Converging Technologies program:

Staffing

- $\quad$ hiring for interdisciplinary programs; make-up of hiring committees; departmental or interdepartmental home for interdisciplinary hires

- criteria for promotion, tenure and merit of interdisciplinary faculty, when the job description specifies that the position is to service a non-traditional, interdisciplinary field

- encouraging (and making it possible for) existing faculty to contribute to CT programs

$\underline{\text { Curriculum }}$

- ensuring a proper liberal-arts-worthy balance of breadth and depth in CT programs

- finding appropriate academic "homes" for CT courses, when they do not neatly fit into existing disciplinary boxes

- creating policies for staffing interdisciplinary team-taught courses

- integrating CT into the new general education curriculum for all Union students, and recommending homes for $\mathrm{CT}$ courses

- considering the proper role of CT courses in disciplinary majors and minors

$\underline{\text { Space and Facilities }}$

- planning for and allocation of space and facilities for CT faculty, research, and academic programs

- determining the feasibility of shared, interdisciplinary teaching and research facilities, including location, scheduling, and maintenance of space and instruments.

\section{Budgets}

- allocation of budget for CT faculty, research, and CT academic programs

\section{Publicity and Fundraising}

- $\quad$ promoting CT programs, both internally and externally, especially in admissions, grantwriting, and fundraising

- reviewing proposed CT partnerships 
We have appointed a Converging Technologies Implementation Council, comprised of faculty and academic administrators, to help identify and recommend policies to address these potential barriers to creating the technical literacy.

We view increasing technical literacy as more than an opportunity. We, too, feel a sense of urgency.

\section{Bibliography}

${ }^{1}$ K. Eric Drexler, Engines of Creation: The Coming Age of Nanotechnology, 1986

${ }^{2}$ See http://www.union.edu/CT

3 George Bugliarello, "A new Trivium and Quadrivium," Bulletin of Science, Technology and Society, 2003.

4 Traditional liberal learning is generally recognized to include the arts, humanities and the sciences. In the minds of many today there is little difference between the terms "science" and "technology," with technology often being viewed simply as applied science. However, historically these terms have very different meanings. The meaning of the word "science" comes from the Latin verb "to know," and refers to mental labor. However, the word "technology" comes from the Greek word "techne," (art or craft), and refers to manual labor. Early technologists were presumed to use their hands and not their minds, and became the essence of the "trades." Consequently, the liberal arts has for centuries represented the opposite of professional or vocational "training". The servile arts were skills learned solely for the sake of doing something for pay. For example, teachers can be trained, but philosophers must be educated.

By the Middle Ages the liberal arts had solidified into seven arts, organized in two sets. The first three (trivium) were grammar, logic, and rhetoric, and the remaining four (quadrivium) were advanced study in arithmetic, geometry, astronomy, and music. The trivium focused on thought and communications, resulting in the conferring of a Bachelor of Arts degree (and the status of "gentleman"). The quadrivium was more advanced in the sciences of the time and produced the Master of Arts degree. Today the trivium has become the literacy required to liberate people from a life of social servility, and, with a little imagination, the modern quadrivium can be viewed as the professional, scientific and technical disciplines.

${ }^{5}$ David P. Barash, "C.P. Snow: Bridging the Two-Cultures Divide," The Chronicle of Higher Education, November $25,2005$.

${ }^{6}$ Mihail C. Roco, and William Simms Bainbridge, National Science Foundation (2002). Converging Technologies for Improving Human Performance. (Arlington, VA)

7 "Given that the stakes for the world are so high, the decisions about the course of research, what to do with our knowledge, and what technological possibilities should be developed cannot be left in the hands of scientists, business interest, or government officials." Dalai Lama (2005), The Universe in a Single Atom: The Convergence of Science and Spirituality. (New York: Morgan Road Books).

8 " ....we have the greatest chance of coming up with ground-breaking insights at the intersection of different disciplines or cultures." Quotation from "Frans Johansson on the Medici Effect," Ubiquity, Volume 5, Issue 31, Oct. 6 - 12, 2004 (http://www.acm.org/ubiquity/interviews/pf/v5i31_johansson.pdf)

9 TfAAP is administered through ITEA and funded by the NSF and NASA. See http://www.iteaconnect.org/TAA/TAA.html

10 "Liberal Outcomes, A Preliminary Report on Student Achievement in College," AAHE, 2005. (www.aacuedu.org/advocacy/pdfs/LEAP_Report_FINAL.pdf)

11 Technologies such as the media of art, the instrumentation and reproduction of music, and the media and transmission of language. When the European Union published its white paper, "Foresighting the New Technology Wave: Converging Technologies - Shaping the Future of European Societies, by Alfred Nordmann (European Commission Report, 2004) they ambitiously identified the following fields: "Nano- Bio- Info- CognoSocio- Anthro- Philo- Geo- Eco- Urbo- Orbo- Macro- Micro- Nano-."

12 Abbott and Masterman, "Working Paper on Literacy No. 2", Centre for Literacy, 1997.

${ }^{13}$ Dalai Lama, op. cit., p. 12 
${ }^{14}$ Mihaly Csikszentmihalyi, "The Future of Happiness," in James Brockman, ed., The Next Fifty Years: Science in the First Half of the Twenty-First Century. (New York: Vintage Books, 2002), pp. 102-103.

15 "Project Kaleidoscope (PKAL) is one of the leading advocates in the United States for building and sustaining strong undergraduate programs in the fields of science, technology, engineering and mathematics (STEM)." See http://www.pkal.org/

${ }^{16}$ Richard Barke, Eliesh O'Neil Lane and Kenneth Knoespel, "Sustainability and the Convergence of Engineering and Liberal Arts Education," Prepared for 4th POSTI International Conference, 2001, p. 2.

http://www.esst.uio.no/posti/workshops/barke.pdf

${ }_{17}$ Committee on Facilitating Interdisciplinary Research, National Academy of Sciences, National Academy of Engineering, Institute of Medicine (2004). Facilitating Interdisciplinary Research (Washington, DC: National Academy of Engineering), available from http://www.nap.edu/catalog/11153.html 